\title{
Socio-economic Impacts of Tourism in Lumbini, Nepal: A Case Study
}

\author{
Pradeep Acharya*
}

\section{Introduction}

Tourism is a very familiar affair in human life. It has been an industry of vast dimensions and ultimately supports economic growth and social development. In order to promote tourism in Nepal, the ninth five year plan has made a 20 year long strategic programme. The main objective of this programme is to develop Nepalese tourism up to the desirable standard. As far as the 20 years long-term tourism policy is concerned, our government has decided to increase the arrival of tourists in average 12, 47,830 every year. And expected income of foreign currency to be 1663.6 million dollar every year. And the average staying of the tourists extended up to 15 days (Nepal Tourism Board, 2000). The Ninth five-year plan says the government is serious about the uplifting of Nepalese tourism, which needs great care and protection. "For the constant development of the Nepalese tourism, it has been commonly decided to give equal priority to some other factors, which do also affect the tourism sector directly. Such as development and expansion of tourism sites, necessary infrastructure for tourism, promotion of tourism market, improvement in civil aviation, protection of environment and involvement of private sector in the promotion of Nepalese tourism, etc" (The People's Review 2001). Hence long term vision is to promote village tourism for poverty alleviation including ecotourism and domestic tourism. Recent development on tourism is highly concentrated on development of trained human resources which is based on quality of services provided to tourists. But many areas of the country are still deprived of basic tourism facilities.

Lumbini is one of the major tourist destinations of Nepal, where different development activities have been going on from different sides. A Master Plan for the Development of Lumbini, including numerous engineering and archaeological studies was completed in 1978, by an architect Kenzo Tange that has its objective to restore an area of about 7.7 square kilometers, to be known as the Lumbini Garden. But the desired targets are yet to be achieved. It is to be noted that meeting of World Conservation Society held during 1- 6 December 1997 has included Lumbini as one of the World Heritage Site. It is only one cultural site we have other than the natural Everest. Need to promote tourism is very important for our country both from economic and cultural concern. So we are to develop resources i.e. destination promotion to attract visitors which will give us money as well as recognition to the world. In this regard government of Nepal has been carrying out Tourism for Rural Poverty Alleviation Programme around Lumbini.

The main objective of the study was to collect information about existing state of tourism in Lumbini not with any specified hypothesis and theoretical framework. I investigated the extent and impacts of tourism among the people of Lumbini ideal village development committee of Rupandehi district, Nepal during the year 2001 AD. An attempt has been made to demonstrate what people actual feel about the incidence of tourism and its socio-cultural impacts. Effort has been provided to see whether the tourism is helpful in generating employment and increased income. An analysis of four data sets (the household survey of 123 samples out of the finite universe of 1234 households, interview of 25 conveniently met tourists, total 12 hotel owners/staffs, 3 key informants deliberately selected and vdc office provided information) as well

\footnotetext{
* Mr. Pradeep Acharya is a Teaching Assistant (Anthropology) at the Mahendra Multiple Campus, Baglung, Nepal.
} 
as non participant field observation shows significant numbers of impacts of tourism in the study area. The research results indicate that, in number of respects, tourism is favorable for the people.

\section{Tourism in the Wider Context}

People believe that tourism is a service industry that takes care of visitors when they are away from home. Some restrict the definition of tourism by number of miles away from home, overnight stays in paid accommodations, or travel for the purpose of pleasure or leisure. Others think that travel and tourism should not even be referred to as an industry. Hunt and Layne (1991) acknowledge the problems of defining travel and tourism. They say that travel was the most accepted term until 1987 and since that time tourism is the accepted term used to "singularly describe the activity of people taking trips away from home and the industry which has developed in response to this activity". The evolved definition of Smith and Eadington (1992) simply states that "tourism is in fact a significant social institution" (Lowry, 1994).

To travel for economic or religious reasons (e.g. to pilgrimage sites) is an ancient human activity as any one posses (Callimanopulos, 1982: Fisher, 1986: 37). Pilgrimage is the opening of tourism in Nepal. Piligrimage by Hindu and Buddhist saints to different parts of Nepal are examples. Poudel(2059) noted that, Fa Hein (403 AD), Huen Sang (366 AD) both from China visited Lumbini, which is very important. Religion has been a powerful force which has long caused people to travel to religious centers in many parts of the world. Travel to the ancient cities of Palestine and Christendom, Mecca, Medina and Bangkok is part of world folklore history (Modi, 2001: 18). The root of tourism in Lumbini too is based on religious interest to the great extent i.e. religious tourism.

The Jakarta conference concluded that tourism employees, as culture brokers, play important roles at all levels: the private and public sectors and institutions must play informed roles in bringing tourism and the host culture into harmony; those sustainable forms of tourism without having accepted tourism itself (Modi, 200: 10). Tourism Studies in academic sector both in private and government sector have been started up to postgraduate degrees in Nepal. It justifies the need of experts in the tourism sector. Different festivals organized by different destinations like Pokhara Street Festival, 2003 etc, Baglung Festival, 2060, Sauraha year, 2060, Ghale gaon festival, 2003 and many others are the examples of the local peoples' interest in tourism promotion from both domestic and international importance which not only accelerates business activities but popularizes the identity of the place. It justifies the day by day increasing interest of people in tourism development around their area.

\section{Destination: The Lumbini Garden}

Destination is a central object in the tourism. It is the item that exerts a pull on the tourists from different areas. It is the one that motivates tourist to travel. Therefore the secret of destination is of prime importance that should never be undermined. First of all in tourism related studies a detailed listing of all resources which have some connection with tourism should be carried out. This is called Tourism resource audit (Clarke \& Godfrey, 2000: 72). Such a resource inventory should include the following: What could a visitor see in this area which might be of interest?; What are the different types of attractions they could visit?; What types of services would they require?; What different activities could they do during their stay?; If staying overnight, what accommodations are available? etc.

Lumbini is situated in central Tarai plain of Nepal, about $300 \mathrm{~km}$ west of Kathmandu. Although its elevation is 105 meters above sea level, himalayan foothills are only $24 \mathrm{kms}$ away and on clear days, Dhaulagiri peak $(8,167 \mathrm{~m})$ is visible, $130 \mathrm{kms}$ due North. Siddarthnagar is the nearest town 
with an airport (Gautam Buddha). Highways connect this town with Kathmandu (east) via Chitawan, rich in wildlife and Pokhara (north), the destination for trekkers. It has a frost free dry winter and a hot wet summer. The average annual rainfall is more than $2500 \mathrm{~mm}$. August (Srawan/Vadra) is the wettest month, usually with a minimum of $1000 \mathrm{~mm}$. The temperature in April, May and June exceeds 40 degree centigrade and during January it declines up to 9 degree centigrade. The winter is dry and relatively cool; during the daytime, however, even in December and January, the temperature can go up to 25 degree centigrade or more (Nepal Tourism Board, 2000).

Much of the tourist appeal in the Lumbini is based on the continued interest of the world people in the Buddha and Buddhism. Lumbini is one of the most important destinations of Nepal from the cultural aspect. The history says that travelers visited the site from ancient times. Due to the lack of proper planning and implementation, trained tourism workers, aware local hosts, it is still not developed as desired. Mainly pilgrims visit the area. Country's main attraction of mountaineering, trekking and adventurous are not available there. According to CBS (2000) piligrimage lies in the third main purpose of visiting Nepal and first and foremost in case of Lumbini.

The tourism resource inventory in this destination begins from the Lumbini Sacred Garden which encircles the ancient heritage of Buddha's birthplace, is the main thing that the visitors come to observe. The Ashokan Pillar, erected by the Indian emperor Ashoka which has an inscription in Brahmi script is the vital historic item of interest for the visitors. Cultural Centre is the other attraction. Cultural Center is dedicated to world peace. It is composed of three of the major buildings of the entire Lumbini development. These are Lumbini Museum, Auditorium, and Lumbini International Research Institutute complex. These buildings are intended to add to the cultural diversity of the activities at Lumbini. The Lumbini Museum embraces relics from the life of Lord Buddha and displays the findings of the archaeological work done. We can see Mauryan Kushana coins, religious manuscripts, terra-cotta, stone and metal sculpture and icons. The Auditorium is envisaged as a multi-purpose hall to be used for national and international congresses. The Lumbini International Research Institute has an archive of over 7,500 books. Many of the tomes are rare, and are written in Nepal Bhasha (Newari), Nepali, Hindi, Japanese, English, French, German, Italian, Sinhalese, Burmese, Thai and Pali. Two monastic enclaves, one each for the Mahayana and Hinayana schools of Buddhism, are located along the central link, separated by a green zone. Within these areas, land is available for the construction of facilities by religious traditions. The Monastic Complex includes 42 plots of various sizes, with 13 for Hinayanist on the east side and 29 for Mahayanist on the west side of the central canal. Meditation facilities for the visitors are available in such enclaves. Another attraction could be a crane sanctuary where hundreds of cranes are protected. This sanctuary along with the greenery can definitely be of interest for nature lovers. It has added flavor in the gold by adding a natural attraction on the cultural destination.

In addition, there are some other areas related to Buddha's life that have equal importance as the Lumbini does. Tilaurakot, the next archeological site, is located $27 \mathrm{kms}$ to the west of Lumbini. Ararakot, lies about 9-km northeast of Tilaurakot. Gotihawa lies $5 \mathrm{kms}$. Southwest of Taulihawa town. The place has ruins of ancient habitation, stupas and monasteries. Kudan is located $2 \mathrm{~km}$ southwest of Taulihawa on way to Gotihawa. Niglihawa is situated $7 \mathrm{~km}$ northwest of Tilaurakot. Sagarhawa lies $3.5 \mathrm{kms}$ north of Tilaurakot and west of Banganga river. Devadaha lies $34 \mathrm{~km}$ northeast of Lumbini near the village of Khairhani. There are large archaeological mounds near the village. Ramgram lies $4 \mathrm{~km}$ south of Parasi town in Nawalparasi district. The remains of stupa and monastery as mounds are beside the bank of Jahari River in Kerwani village. 
There are 15 lodging hubs involving both private hotels and religious quarters. The sum of 245 rooms having 730 beds is the total carrying capacity of hotels of Lumbini per night out of which $39.5 \%$ rooms, which comprises 199 beds, are deluxe and rest of all provide general service which are variable hotel to hotel regarding different facilities (Acharya, 2001:65).

The average rate per person per night in deluxe hotels ranges from Rs. 3000 to Rs. 7000 . And the other general hotels provide beds within Rs. 100 to Rs. 500. The rate also varies as par the nationality of visitors such as Nepalese, Indian and SAARC countries and other foreign nations etc. Nepalese and Indians get beds relatively in cheaper rate than other visitors. Personal bargaining between hotel and tourist is the common system of fixing up the charge (Acharya, 2001:66). In addition to these, free accommodations too are available in the religious quarters. They do not have fixed charges but the donation box is open for optional contributions.

\section{The Host Society}

Destination communities are the basic element of modern tourism. They are the focal point for the supply of accommodation, catering, information, transport, and services (Clarke \& Godfrey, 2000:3). The people are the hosts who welcome tourists and preserve and sell the destination.

Lumbini ideal VDC is the largest one regarding population and area among the four villages in touch with the Lumbini Garden; Lumbini Ideal, Madhuwani, Ekla and Tenuhawa VDC encircles the Lumbini Garden from four sides. In the north of the village are the Lumbini sacred garden and Tenuhawa VDC, Bhagwanpur and Amari VDCs in the south and Madhubani VDC in the east and Kapilbastu district in the west separated by Kothi river. The total area of the village is nearly 6000 Bighas (4000 Hactares). Around 12000 people live here distributed among 1234 households. Out of which males consist more than fifty percent of the total population (VDC office, 2001).

Mainly two religions i.e. Islam and Hinduism are extant in the village. Household in nearly equal numbers represent both of these religion. The Hindu majority $(51.38 \%)$ consists of Brahmin (6\%), Dhawal (5\%) and Yadav (4.86\%) and others such as Baniaya, Gupta, Nau, Lohar, Badhai, Kanhar, Lodha, Bhuz, Teli, Kayastha, Lonia, Manjhi, Pasi, Murau, Natua, Gosain, Gadariaya, Jaisawal etc. Muslim or Islam people (48.62\%) consists of Fakir, Hajam, Chudiyar, Hakim, Khan, Miya, Shekh etc (VDC office, 2001).

Each religious group identifies themselves as a distinct group regarding their social structure, kinship system, cultural values, worship and prayer pattern, festivals and birth-marriage-death rituals. Within both of the group different subgroups can be observed based on the customary occupations of each.

\section{The Tourists}

Tourists are the key actors in the tourism activity who travel and visit the destination in order to satisfy their purposes on the behalf of the people living around the area. Tourists are the key actors in the sense that they move and travel from their original location while the society and destination remain where they are. Obviously the tourists are dynamic actors whereas society and destinations are static within the domain of the tourism activity in the place.

Purpose of visit or the motivation for travel is the main driving force that makes tourists move away from their home to a destination where they can get what they want. The sixty percent of the tourist respondents were in fact interested in Buddha and Buddhism that's why they moved to get their feet over the land where the Buddha was born i.e. pilgrims. According to the Kathmandu Post Daily (Jan 9, 05), out of the tourist of 66 countries visiting Lumbini, Srilanka (12217; 
$32.24 \%)$ and Thailand $(7735 ; 20.41 \%)$ have been at the top two countries; both representing Buddhism as a religion of the majority. Obviously, the nature of destination is an attestation for this fact.

When tourists reach the very destination, some return back to their base camp in the evening whereas some extend their stay at the destination. Such duration of stay depends upon two things; first the specific objective (such as meditation, research, official works) of the visitor and second the facilities of accommodation available in the area. 10 respondents were night staying visitors out of 25. Their stay duration ranges from 1-3 nights to 15-30 nights. In this category the short stayers upto 3 days were researchers and officials while others were meditators, devotees including officials as well.

Okada (1969) observed at various times in 1969 that most tourists, among whom were diplomats from two Southeast Asian countries, did not spend much more than an hour at the garden, arriving in the forenoon by car form India, possibly catering a basket lunch at the site, and departing hastily to reach suitable accommodations by night fall. So, it was the scenario of tourism in Lumbini, more than 3 decades prior to this study. It was due to the lack of basic accommodation infrastructures and moreover due to the visitors being diplomats who seek more comfort and obviously are busy on some other jobs. But today the enough carrying capacity and presence of new structures have facilitated to extend the duration of stay which is definitely a positive aspect of tourism in Lumbini.

Number of tourist's arrivals in Lumbini too has leaped forward. Even though some years show a decline, overall trend is upward. Lumbini was visited only by 1023 tourists during 1964 (Okada, 1969) has been visited by 16780 tourists during 2000 (Acharya, 2001). Lumbini has happened to be a purpose meant for visitors' prior from the time when the Lumbini fall out to be the birthplace of the Gautam Buddha. Owing to the being there of the blessed Lumbini garden, the number of visitors is increasing each year i.e. $35.7 \%$ up in 2004 (28053) as compared with 2003 (37892) (The Kathmandu Post, Jan 9, 05).

\section{Impacts}

Tourism is an economic activity that is imposed, or at least grafted, on a pre-existing set of economic activities and traditional ways of life (Price \& Harrison, 1996: 1). Tourism is a product of three main elements; destination, hosts and the tourists. Tourism is a process which obviously affects various aspects of society and culture. Primarily its impact is of economic nature. Sharma (2059) states that the contribution of tourism in gross foreign exchange is 15 to 17 percent and the influence of tourism is also centered in some specific areas only not throughout the whole nation but it does not mean to underestimate the tourism because we know a very little about the multiplier effect of the tourism; we must take account of the foods, vegetables and fruits that the tourists take as well as the employment plus the crafts that the tourists purchase.

According to Godfrey and Clarke (2000), socio-cultural change relate to local quality of life and sense of place. Positive change in the quality of life could be as follows; personal income increases, helps to improve living standards for those more directly involved in industry, supports the diversity of restaurants and other cultural entertainment, influence the assortment of goods for sale in many local shops that would not be available in the same amount if tourism did not exist to support them, park areas are often improved, street furniture and design criteria introduced, greater care and attention placed on overall environmental quality, new opportunities etc. And in contrary negative changes in the quality of life could be as follows; local shops overcharging, petty theft from cars and accommodation, more serious personal assault etc. Regarding the sense of place, positive changes could be as follows; revitalizing local culture and traditions, enriching 
local understanding and interest in history and culture, a sense of pride in local heritage, celebrations/festivals can become tourist attractions, crafts promotion and production in large scale etc.

All these impacts or changes were observed. Tourism has influenced the society of Lumbini in both the local quality of life and the sense of place. In fact the movement of the outsiders in any area could not be impact less; of course the level of impact can vary on various aspects.

From the economic aspects job generation by hotels /lodges is a very important impact of tourism in Lumbini. It is obvious that the hotels and lodges are meant for the visitors who do not have home out there. The entry of outsiders obviously requires the home to live in for food and shelter and consequently local people have to work for it. Every hotels and quarters hold paid staffs and workers as par the nature and size of their operations. Total of 103 personnel are busy in undertaking of accommodation base in Lumbini out of them $72.81 \%$ are skilled and non-skilled workers. In order to make destination more interesting, according to the master plan, different structures have been under construction in the Lumbini, which requires workers. More than 50 people from the VDC are involved as the workers/laborers in the new construction site of the Lumbini where different structures like Monasteries, Stupas, Temples and Hotels etc. are under construction. They earn Rs. 1500 to 3000 per month during working periods. This is another important impact of tourism development in Lumbini regarding the employment (Acharya, 2001).

Generation of new economic activities like hiring of cycles, parking of vehicles, taking care of tourist's goods for the time being, guiding etc. have come into view. These events have not been wholly institutionalized as a separate trade but make available an extra profit to the indigenous population. The common public free of work or with some other enterprises carry out these works. Such new areas of income emerged as a result of tourism which is not only and economic phenomena but an influential cultural phenomenon too because engagement in different activities brings changes in the daily life styles. Employment generation and formation of new economic activities raise the income of the people which obviously affects living standard. From our sample survey $7.31 \%$ of the respondents have not increased their income from tourists directly. The jobholders both private and government involve this category. The generations of the jobs in the private sector are due to tourism but they are not paid directly by the tourists. And the $43.08 \%$ farmers though do not deal directly with tourist have felt an increment in income around two to three thousand rupees due to the increased demand of food grains to feed the tourist flow. Nearly the half $49.61 \%$ are found to be directly benefited from the tourists. The small $(1.62 \%)$ part involving hoteliers have made money up to large extent i.e. above ten thousands. And the transport owners, comprising $2.43 \%$ of the total, lie at the second level regarding the level of income from tourists. Another $32.52 \%$ involve the rickshaw pullers, gift shops etc. They lie at the third level. The students comprising nearly $5 \%$ too earn money working as guide for tourists. All these economic impacts (employment, new economic activities) of tourism affect the daily life style of the people and consequently the socio-culture slowly but surely.

From the socio-cultural point of view alteration in the occupation is a key change caused by tourism. Obviously the local people seek those economic activities with more income and chances of further expansion. Owing to different internal and external reasons people tend to make an alteration in their current works. They either change the occupation or add extra activities as an occupation. Out of the total 123 responses $44 \%$ have altered their present profession. The $43 \%$ of the total occupation altering respondents have added wage laboring or rickshaws pulling work in farming. Similarly $9 \%$ work in government and private offices in addition to farming. They represent both self-sustained and un-sustained group of respondents. And nearly $21 \%$ of the respondents have added hotel and general trade. Changes of profession 
have been seen among $26 \%$. The $21 \%$ of such respondents have quitted teashop and transformed into gift (mala) shop because it generates more income directly from the tourists. And 2\% (labourers) have invested on general stores; by still not giving up the labouring. Similarily, the 4\% farmers have altered to transport service with bus, jeep and tractors. The actual amount of income generated by tourists is problematical to recognize for the reason that the tourism has influenced all segments of the economic system. Such alterations are mainly due to the income i.e. chances for generating more income. Furthermore, the professions involving direct interaction with foreigners is more charming for them.

Fisher (1986: 50) noted that, Sherpas wear either their own Tibetan costumes or the western but not a Nepalese dress. Obviously the people either do (eat, wear) what they are habituated of doing within their culture or they copy some favourable items from them who are in repeated contact with them. In case of Lumbini too, more than $40 \%$ of our respondents have felt changes in their dressing patterns as a result of the tourism. Nearly $2 \%$ of the respondents have realized small change in food habits and tastes. Actually the food habit and taste to which the local people are accustomed from many years is very hard and needless to be modified though the need for tourist's satisfaction have diversified the menu too. Such a diversification of menu is very important impact from the cultural standpoint. The group of nearly $15 \%$ realized all of the changes stated above and also added that the local people's view toward their daily life too has got some modifications; it is what takes place inside one's attitude. Money minded ness caused by tourists' spending pattern is what made them change professions. The information about foreign culture, which the local people can daily observe has made them attracted toward the accessories like cameras, vehicles, watches etc as well as the intention to go abroad to enjoy foreign life style and earn money. Tourism event in Lumbini has influenced the concealed attitude of the local people along with some modifications in their visible culture.

From the environmental aspect Lumbini has been facing some impacts which cannot be watered down though not to the great extent. Along with the gradual development of tourism, construction of different structures is necessary. The Lumbini full of Sal forest before the adoption of the Lumbini Development Master Plan in 1978 (Okada, 1969) has now been converted to a concrete park representing Buddhism and other kinds of basic infrastructures. In fact the outlook of the area has taken a new look. It is the most important environmental impact induced by tourism. Besides the people both the tourists and the locale experience air pollution caused by the dusty roads and the poor conditioned vehicles but to check this government has applied some electric vehicles for transportation, which is the desired step. The solid waste problem is not so remarkable because the site for garbage disposal is adequate in the area. Generally the visitors consume the locally available food and do not need to carry extra food packets. Camping and tenting are not favorable in the area. The local people fulfill the need of firewood and pasture from the existing forest of Lumbini. Majority of the people use Cow dung as the main source of fuel so the pressure for firewood is not so severe but the grazing problem exists.

The locale socially has inclined toward the need of tourism. The tourism development in Lumbini has reinforced the functional unity among the two diverse nature of religion. Both of the religious communities have started to consider Lumbini garden as a collective heritage. This justifies the changes in the sense of place among the people. Unless the people understand what they have in their place which of interest for the foreigners abroad, tourism development is hardly possible. This is a very important impact, which is more than the economic impacts.

\section{Conclusions}

Tourism can be termed as a socio-cultural institution with different economical, environmental, psychological, and political dimensions. Its impacts rest on host society whose ways of life are 
affected and on the tourists who take it as a very important part of their life time. Fisher (1986:58) noted that in short run tourism is enormously popular with Sherpas of Khumbu. Obviously, tourism itself as a peaceful phenomenon can be well linked in no time, once it has firmly started. Lumbini, too has been attracting and accommodating tourists from different parts of the world from many years and furthermore this trend is increasing.

It can be straightforwardly confirmed that the tourism industry in Lumbini has become a job generator; both service oriented and product oriented. Increased income by job generation help raise standard of living. In addition the diversification of various new economic activities can lessen the big social problem of unemployment. People of the area welcome tourism as they have realized its importance, particularly from the economical aspect. It is a matter of fact that a poor country like Nepal should put economic concern at the top.

Tourists not only bring money to region, they also carry along with them a strong and visible lifestyle. Their dress, food habits and merry making style all brings some newness and uniqueness to the area of their visit. By nature human adopts new thing or manners in which they feel comfortable. Sometimes, new habits are acquired from strangers just to get a new taste Kunwar (2002: 104-5). Of course the economical aspects only should not be overemphasized. Everyday acquaintances with the foreigners and outsiders have made it easier to be familiar with the life style of the others. They are able to comprehend the similarities and differences among the people representing various nations around their courtyard. Interaction and observation of this kind have lifted their level of thinking resulting in a positive mind-set toward others and themselves. People have accepted some new favourable cultural traits regarding the diversification of menu or costumes without cutting down their social values constituting their identity. Familiarity with different languages has not only made the communication easier and better but also has added a new and useful skill in their life. Tourism has facilitated the development of the sense of place among the people. They are conscious about the heritage that has been preserved from many years. The locales have slowly but surely come to be aware of the secret which is of interest for the people around the world. Consequently more care and protection is supplied to the cultural heritage collectively by them. Such a joint effort not only improves the attraction of the destination but also unites people together.

Lumbini needs to develop tourism in ways compatible with maintaining and enhancing the lifestyle and sense of community that presently exists, and in ways that conserve the natural and cultural resources. For such a many objectives to be fulfilled, government has been carrying out the Tourism for Rural Poverty Alleviation Programme (TRPAP) in Lumbini.

\section{References}

Acharya, P 2001: Impact of Tourism in Economic and Sociocultural Aspects of Lumbini VDC; An Anthropological Case Study, a Master's Level Thesis, Tribhuwan University

Fisher, JF 1986: Tourist and Sherpas, Contribution to Nepalese Studies, 14(1) pp37-61

Godfrey, K and Clarke, J 2000: The Tourism Development Handbook: A Practical Approach to Planning and Marketing.

Kunwar, RR 2002); Anthropology of Tourism: A Case Study of Sauraha, Adroit Publishers, India

Lowry, LL 1994: What is Travel and Tourism and Is There a Difference Between Them; A Continuing Discussion, New England Journal of Travel and Tourism, England (2829)

Modi, S 2000); Tourism and Society: Cross Cultural Perspective, Rawat Publications, India

Nepal Tourism Board 2000: Lumbini; the Fountain of World Peace. His Majesty's Government, Nepal

Okada, FE 1969: The Lumbini Garden Area, Rupandehi District Nepal; A Socioeconomic 
Survey, His Majesty's Government / United Nations

Poudel, P.C. 2059: Ghandruk le pachhutaunu naparos (in Nepali). Bikas, year 10, vol 22, Atmanirvar Vikas Manch, Kathmandu (pp 9-11)

Price MF/Harrison D 1996: Fragile Environments, Fragile Communities? An Introduction: People and Tourism in Fragile Environemnts, John Wley and Sons Ltd.

Sharma, P 2059: Paryatan Bikas le Garibi Ghatchha (in Nepali). Bikas, Year 10, vol 22, Atmanirvar Bikas Manch, Kathmancu (pp 4-8)

The Kathmandu Post National Daily, Jan 9, 05, Kantipur Publications, Kathmandu

The People's Review 2001: Political Upheavals Mar Nepalese Tourism; Jan 18- 24, Kathmandu, Nepal 